\title{
TOFA suppresses ovarian cancer cell growth in vitro and in vivo
}

\author{
SHU LI ${ }^{1,2}$, LIHUA QIU ${ }^{1}$, BUCHU WU ${ }^{1}$, HAORAN SHEN ${ }^{1}$, JING ZHU ${ }^{1}$, \\ LIANG ZHOU ${ }^{1}$, LIYING GU ${ }^{1}$ and WEN DI ${ }^{1,2}$ \\ ${ }^{1}$ Department of Obstetrics and Gynecology, Ren Ji Hospital, School of Medicine, Shanghai Jiao Tong University, \\ Shanghai 200127; ${ }^{2}$ Shanghai Key Laboratory of Gynecologic Oncology, Shanghai 200127, P.R. China
}

Received January 21, 2013; Accepted May 17, 2013

DOI: $10.3892 / \mathrm{mmr} .2013 .1505$

\begin{abstract}
A characteristic feature of cancer cells is the activation of de novo fatty acid synthesis. Acetyl-CoA carboxylase (ACC) is a key enzyme in fatty acid synthesis, accelerating the reaction that carboxylates cytosolic acetyl-CoA to form malonyl-CoA. ACC is highly expressed in several types of human cancer and is important in breast and prostate cancer cell growth. The aim of the present study was to investigate the effects of 5-tetradecyloxy-2-furoic acid (TOFA), an allosteric inhibitor of ACC, on the proliferation and cell cycle progression of the ovarian cancer cell lines COC1 and COC1/DDP. TOFA was found to be cytotoxic to COC1 and COC1/DDP cells with a $50 \%$ inhibitory concentration $\left(\mathrm{IC}_{50}\right)$ of $\sim 26.1$ and $11.6 \mu \mathrm{g} / \mathrm{ml}$, respectively. TOFA inhibited the proliferation of the cancer cells examined in a time- and dose-dependent manner, arrested the cells in the G0/G1 cell cycle phase and induced apoptosis. The expression of the cell cycle regulating proteins cyclin D1 and cyclin-dependent kinase (CDK) 4, as well as the expression of the apoptosis-related proteins caspase- 3 and $\mathrm{Bcl}-2$, were detected by western blot analysis. Cyclin D1, CDK4 and Bcl-2 protein expression was inhibited by TOFA, while caspase- 3 was cleaved and activated. To the best of our knowledge, the present study demonstrated for the first time that TOFA inhibits COC1/DDP cell growth in ovarian tumor mouse xenografts. By inhibiting ACC, TOFA may be a promising small molecule agent for ovarian cancer therapy.
\end{abstract}

\section{Introduction}

Ovarian cancer is the most malignant type of gynecological cancer. There are 225,000 new cases worldwide every year, and 140,000 females succumb to this disease each year (1).

Correspondence to: Professor Wen Di, Department of Obstetrics and Gynecology, Ren Ji Hospital, School of Medicine, Shanghai Jiao Tong University, Shanghai Key Laboratory of Gynecologic Oncology, 1630 Dong Fang Road, Shanghai 200127, P.R. China E-mail: diwen163@163.com

Key words: acetyl-CoA carboxylase, ovarian cancer, 5-tetradecyloxy-2-furoic acid, cell cycle, apoptosis, nude mice
Most patients are diagnosed in advanced stages, since the anatomical position of the ovary is deep within the abdomen. Treatment of ovarian cancer includes cytoreductive surgery and chemotherapy based on a combination of paclitaxel and cisplatin. More than $80 \%$ of patients respond to initial therapy, although some patients with advanced stages develop recrudescent ovarian cancer that is resistant to platinum-based chemotherapies $(2,3)$. Therefore, it is important to develop more effective therapies for treating ovarian cancer.

Acetyl-CoA carboxylase (ACC) is a rate-limiting, biotin-dependent enzyme involved in fatty acid synthesis. ACC catalyzes the carboxylation of cytosolic acetyl-CoA to malonyl-CoA. This is the first step in the fatty acid synthesis pathway that is controlled by a balance between active and less active forms of ACC. Malonyl-CoA is a dual-functioning compound that donates two-carbon units to fatty acid synthesis and controls fatty acid oxidation in the cytoplasm by inhibiting acylcarnitine transfer to mitochondria. Adjustment of malonyl-CoA levels ensures that these two processes do not occur simultaneously. Eukaryotic ACC contains biotin carboxylase (BC), biotin carboxyl carrier protein (BCCP) and carboxyltransferase (CT) (4-6).

ACC has two isoforms, ACCA (ACC- $\alpha$ ) and ACCB (ACC- $\beta$ ), which are encoded by different genes. In mammals, ACCA is enriched in the liver, adipose tissue and mammary glands, since they are abundant in fatty acids. ACCA is located at the $17 q 21$ locus, while ACCB is located at the $12 q 24$ locus. ACCB is expressed in skeletal muscles and the heart. ACCA catalyzes fatty acid synthesis, while ACCB controls fatty acid oxidation progression $(7,8)$. ACC activity is tightly regulated by reversible phosphorylation, modulation of gene expression, and metabolite-mediated allosteric mechanisms. Several critical ACCA phosphorylation sites have been identified ( $\mathrm{Ser}^{79}$, $\operatorname{Ser}^{1200}$ and $\operatorname{Ser}^{1215}$ ) and they are phosphorylated by adenosine monophosphate-activated protein kinase (AMPK) $(9,10)$. Notably, ACCA is overexpressed in many types of human cancer, such as liver and breast tumors in which lipogenesis is highly activated (10-12). To date, there have been no studies on ACCA expression in ovarian cancer tissues. However, an increasing body of evidence has shown that fatty acid synthesis is required for cancer cell proliferation and survival (13). When ACCA expression is downregulated by small interfering RNA (siRNA), prostate, breast and colon cancer cell proliferation and fatty acid synthesis are immediately inhibited, and apoptosis is induced (13-15). These findings suggest that the regulation of 
ACCA plays an important role in cell growth and apoptosis, and that ACCA may be a potential target in cancer therapy.

5-Tetradecyloxy-2-furoic acid (TOFA) is a cell-permeable small molecule that is an allosteric inhibitor of ACCA. TOFA reduces the availability of endogenous fatty acids required for the generation of phosphatidylcholine, the major phospholipid of cell membranes (16-19). TOFA has been reported to be cytotoxic and to induce apoptosis in the lung cancer cell line NCI-460, the colon cancer cell lines HCT-8 and HCT-15, and the prostate cancer cell line LNCaP. However, the effect of TOFA on ovarian cancer cells has yet to be elucidated $(15,20)$. Therefore, the aim of the present study was to investigate the effects of TOFA on the proliferation and cell cycle progression of the ovarian cancer cell lines COC1 and COC1/DDP.

\section{Materials and methods}

Cell culture. The human ovarian cancer cell lines COC1 and COC1/DDP were purchased from the China Center for Type Culture Collection (CCTCC; Wuhan, China) and were cultured in RPMI-1640 medium (Hyclone, Logan, UT, USA) supplemented with $10 \%$ fetal calf serum (FCS; Hyclone) and penicillin/streptomycin (1:100, Hyclone) in a $5 \% \mathrm{CO}_{2}$ air-humidified atmosphere at $37^{\circ} \mathrm{C}$. Cis-platinum (CDDP, $0.5 \mu \mathrm{g} / \mathrm{ml}$ dissolved in RPMI-1640; Qilu, Inc., Shandong, China) was added to the culture medium of COC1/DDP cells.

Cell proliferation assay. TOFA (Sigma, St. Louis, MO, USA) was dissolved in dimethylsulphoxide (DMSO) to make a $50 \mathrm{mg} / \mathrm{ml}$ stock solution. The cells $\left(1 \times 10^{4}\right.$ cells/well) were seeded in 96-well plates and incubated with TOFA at various concentrations $(0,1,5,10,20$ and $50 \mu \mathrm{g} / \mathrm{ml})$. Cell proliferation was assessed 24,48 and $72 \mathrm{~h}$ following TOFA treatment by measuring the reduction of the tetrazolium salt WST-8 to formazan using the Cell Counting kit-8 (CCK-8) purchased from Dojindo (Kumamoto, Japan) according to the manufacturer's instructions. At each time point, $10 \mu 1$ of the CCK-8 solution was added to each well and cultured at $37^{\circ} \mathrm{C}$ for $2 \mathrm{~h}$. The supernatant from each plate was collected and the absorbance was measured at $450 \mathrm{~nm}$. The inhibition rate of cell proliferation and the $50 \%$ inhibitory concentration $\left(\mathrm{IC}_{50}\right.$; calculated by nonlinear regression) was determined according to the following equation: Inhibition rate $(\%)=[(\mathrm{Ac}-\mathrm{Ae}) /(\mathrm{Ac}-\mathrm{Ab})] \times 100 \%$, where Ae, absorbance of the culture media in experimental wells; Ac, absorbance of the culture medium in control wells and Ab, absorbance of the culture medium in blank wells (21).

Cell cycle analysis. COC1 and COC1/DDP cells were seeded in 6-well plates at a density of $2 \times 10^{5}$ cells/well and treated with or without TOFA ( 5 or $10 \mu \mathrm{g} / \mathrm{ml}$ ) for 24,48 and $72 \mathrm{~h}$. For cell cycle analysis, the cells were centrifuged at $466 \mathrm{x} \mathrm{g}$ for $5 \mathrm{~min}$ and washed twice with cold phosphate-buffered saline (PBS). The cells were fixed with $70 \%$ ice-cold ethanol and stored at $-20^{\circ} \mathrm{C}$. The cells were washed with PBS $24 \mathrm{~h}$ later, treated with RNase A and incubated at $37^{\circ} \mathrm{C}$ for $30 \mathrm{~min}$ according to the manufacturer's protocol. Propidium iodide (PI) was added ( $400 \mu \mathrm{l}$ of a $20-\mu \mathrm{g} / \mathrm{ml}$ solution), the cells were incubated in the dark for $30 \mathrm{~min}$ and the absorbance was measured at $488 \mathrm{~nm}$.
Apoptosis assay. Ovarian cancer cells COC1 and COC1/DDP $\left(2 \times 10^{5}\right.$ cells/well) were treated with TOFA $(0,1,5,10,20$ and $50 \mu \mathrm{g} / \mathrm{ml}$ ) for 24,48 and $72 \mathrm{~h}$. Subsequently, an apoptosis detection kit (Becton-Dickinson, San Diego, CA, USA) was used according to the manufacturer's instructions. The cells were collected by centrifugation at $466 \mathrm{x} \mathrm{g}$ for $5 \mathrm{~min}$, washed twice with cold PBS and suspended in $100 \mu \mathrm{l}$ binding buffer. Annexin V-FITC $(5 \mu \mathrm{l})$ and PI $(5 \mu \mathrm{l})$ were added to the culture media of cells and the cells were incubated for $15 \mathrm{~min}$ at room temperature in the dark. Binding buffer (400 $\mu \mathrm{l})$ was added and fluorescent intensities were determined by flow cytometry at $488 \mathrm{~nm}$ (FACSCalibur; Becton-Dickinson).

Western blot analysis. The cells were washed with cold PBS and harvested by scraping into $50 \mu \mathrm{l}$ cell lysis solution (Merck, Darmstadt, Germany). The cell lysates were incubated on ice for $5 \mathrm{~min}$. After centrifugation at $15,000 \mathrm{x}$ g for $5 \mathrm{~min}$ at $4^{\circ} \mathrm{C}$, supernatants were collected and protein concentration was determined using the Bradford assay (Roche, Indianapolis, IN, USA). The proteins were subjected to electrophoresis on SDS-polyacrylamide gels and then transferred to nitrocellulose membranes. The membranes were blocked in 5\% $(\mathrm{w} / \mathrm{v})$ bovine serum albumin (BSA) containing $0.1 \%(\mathrm{v} / \mathrm{v})$ Tween-20 (TBST). The membranes were then probed with primary antibodies in TBST containing 5\% BSA overnight at $4^{\circ} \mathrm{C}$. Subsequently, the membranes were incubated with horseradish peroxidase (HRP)-linked secondary antibodies at room temperature for $1 \mathrm{~h}$ and washed with TBST thrice. The signals were detected by a chemiluminescence phototope-HRP kit according to the manufacturer's instructions (Millipore, Boston, MA, USA).

COC1/DDP tumor xenografts in mice. Female athymic $\mathrm{BALB} / \mathrm{c}$ nude mice, 4-5 weeks old, weighing 17-20 g were purchased from the Chinese Academy of Sciences (Beijing, China). The study was approved by the ethics committee of School of Medicine, Shanghai Jiao Tong University Shanghai, China. COC1/DDP cells were collected by centrifugation at $300 \mathrm{x} \mathrm{g}$ for $5 \mathrm{~min}$ and suspended in RPMI-1640 medium at a density of $2 \times 10^{6}$ cells $/ 100 \mu$ l. The cells were subcutaneously injected into both right and left flanks of each mouse. Twenty days later, mice were randomly allocated into one of the 2 groups ( $\mathrm{n}=5$ mice/group): i) mice treated with $50 \mu 1 \mathrm{DMSO}$ (control group) or ii) mice treated with TOFA $(50 \mathrm{mg} / \mathrm{kg})$. The drugs were injected intraperitoneally daily for two weeks. Tumor volumes were recorded every two days by measuring dimensions (length and width) with Vernier calipers. The mice were sacrificed four weeks after the final treatment. Tumor weights were measured by a scale. The formula used to determine tumor sizes was $\mathrm{A} \times \mathrm{B}^{2}$ x 0.5236 (A, length; $\mathrm{B}$, width; all measured in $\mathrm{mm}$ ) (22). For histopathological examination, tumors and multiple organs were fixed in $10 \%$ neutral-buffered formalin and wax embedded. The tissues were cut into 4-mm sections and stained with hematoxylin and eosin (H\&E).

Statistical analysis. SPSS 18.0 software was used for statistical analysis. Statistical analyses between the control and treatment groups were performed using t-tests. $\mathrm{P} \leq 0.05$ was considered to indicate a statistically significant difference. 


\section{Results}

TOFA suppresses ovarian cancer cell proliferation. To investigate the effect of TOFA on ovarian cancer cells, COC1 and COC1/DDP cell lines were treated with various concentrations of TOFA (1-50 $\mu \mathrm{g} / \mathrm{ml})$ for 24-72 $\mathrm{h}$, and cell proliferation was assessed. The various concentrations of TOFA used were found to inhibit COC1 and COC1/DDP cell growth in a concentration- and time-dependent manner (Fig. 1). TOFA was also shown to be highly cytotoxic to ovarian cancer cells. The $\mathrm{IC}_{50}$ values of $\mathrm{COC} 1$ and COC1/DDP cells for TOFA were $\sim 26.1$ and $\sim 11.2 \mu \mathrm{g} / \mathrm{ml}$, respectively, after $48 \mathrm{~h}$ of treatment. These data indicate that fatty acid synthesis plays an important role in the proliferation of the ovarian cancer cell lines COC1 and COC1/DDP.

TOFA induces cell cycle arrest. To investigate whether TOFA induced cell cycle arrest in ovarian cancer cells, COC1 and COC1/DDP cells were cultured with TOFA for 24, 48 and $72 \mathrm{~h}$, followed by cell counting using FACScan analysis. COC1 cells treated with TOFA were arrested in the G0/G1 phase. Particularly, treatment with $5 \mu \mathrm{g} / \mathrm{ml}$ TOFA for 48 and $72 \mathrm{~h}$ increased the percentage of COC1 cells in this phase to 50.2 and $51.1 \%$, compared with the percentage of the untreated control groups, 28.1 and $34.4 \%(\mathrm{P}<0.01)$, respectively (Fig. 2B and C). The treatment of COC1/DDP cells with TOFA $(10 \mu \mathrm{g} / \mathrm{ml})$ for $72 \mathrm{~h}$ increased the percentage of cells in the G0/G1 phase from 38.3 (control) to $43.0 \%$ ( $\mathrm{P}<0.05$; Fig. $2 \mathrm{G}$ ). These results indicate that cell cycle progression from the G1 to the $\mathrm{S}$ phase is associated with fatty acid synthesis. To investigate the mechanism underlying cell cycle arrest, the protein levels of cyclin D1 and cyclin-dependent kinase (CDK) 4, two proteins that regulate progression from the $\mathrm{G} 1$ to the $\mathrm{S}$ phase, were examined using western blot analysis (Fig. 2D and $\mathrm{H}$ ). TOFA treatment of COC1 and COC1/DDP cells decreased cyclin D1 protein levels in a dose-dependent manner. However, CDK4 protein levels were increased in TOFA-treated COC1 cells $(1-20 \mu \mathrm{g} / \mathrm{ml})$, followed by a subsequent decrease when $50 \mu \mathrm{g} / \mathrm{ml}$ TOFA was used (Fig. 2D).

TOFA induces apoptosis. TOFA induces apoptosis in human lung and colon cancer cells by inhibiting fatty acid synthesis and inducing poly(ADP-ribose) polymerase (PARP) cleavage and DNA fragmentation (15). To investigate the underlying mechanism of the cytotoxic effect of TOFA on ovarian cancer cells, the ovarian cancer cell lines COC1 and COC1/DDP were treated with TOFA as previously described. Apoptosis was detected by Annexin V staining and FACScan analysis. Western blot analysis was also used to investigate the expression of the apoptosis-related proteins caspase-3 and Bcl-2. Low concentrations of TOFA were found to induce apoptosis in COC1 and COC1/DDP cells. The ratio of apoptosis to cell proliferation was $12.4,42.6$ and $43.9 \%$ in COC1 cells treated with $10 \mu \mathrm{g} / \mathrm{ml}$ TOFA for 24,48 and $72 \mathrm{~h}$, respectively (Fig. 3A). The ratio of apoptosis to cell proliferation was 32.2 and $42.1 \%$ for COC1/DDP cells treated with $5 \mu \mathrm{g} / \mathrm{ml}$ TOFA for 48 and 72 h, respectively (Fig. 3C). Caspase-3 was cleaved and activated while $\mathrm{Bcl}-2$ expression decreased following treatment with TOFA of both COC1 and COC1/DDP cells (Fig. 3B and D).
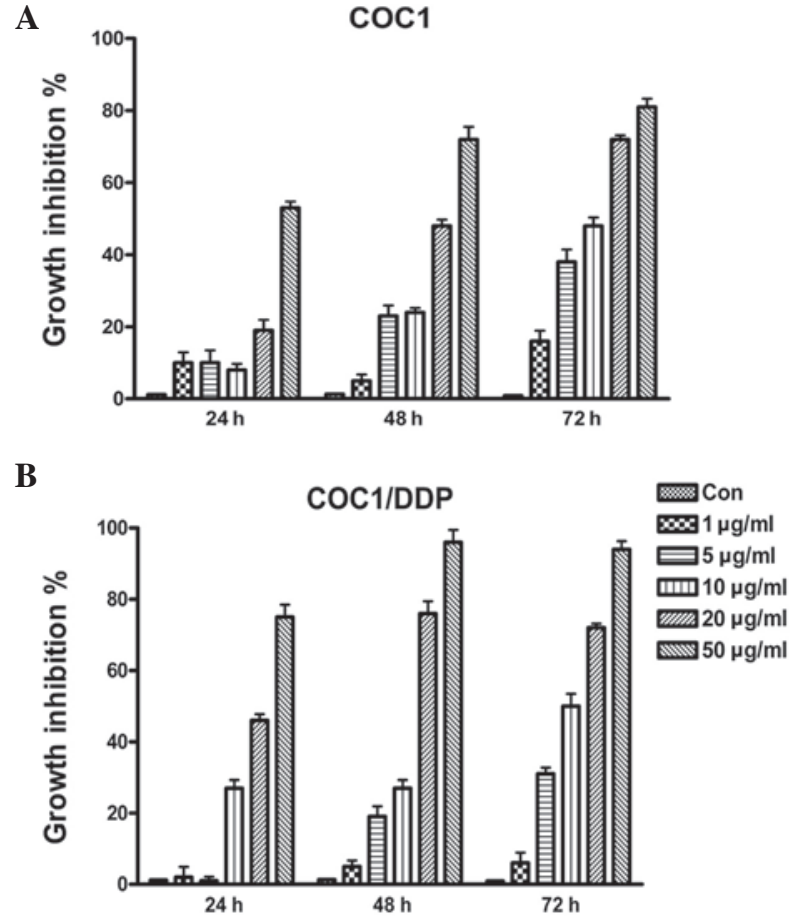

Figure 1. TOFA induces growth inhibition of ovarian cancer cells. (A) COC1 and (B) COC1/DDP cells were treated with TOFA $(0,1,5,10,20$ and $50 \mu \mathrm{g} / \mathrm{ml}$ ) for 24,48 and $72 \mathrm{~h}$. All data represent mean values and error bars represent the $\mathrm{SD}$ of three samples in independent experiments repeated three times. TOFA, 5-tetradecyloxy-2-furoic acid.

TOFA inhibits growth of ovarian cancer xenografts in mice. To investigate whether TOFA suppresses tumor growth in vivo, the effects of TOFA were investigated using a human ovarian cancer mouse xenograft model. COC1/DDP cells were injected into female nude mice, and tumor sizes were measured following TOFA treatment. The tumor growth rate was significantly inhibited by TOFA compared with the DMSO-treated control mice $\left(1649 \pm 356.3\right.$ vs. $5128 \pm 390.4 \mathrm{~mm}^{3}$; Fig. 4A). To test for TOFA toxicity, the effect of TOFA was examined on multiple mouse organs with H\&E staining (Fig. 4B). No toxicity was observed in the heart, liver, spleen, lung, kidney and intestinal tissues (data not shown).

\section{Discussion}

Several studies have suggested that fatty acid synthesis is important in the cellular proliferation of many types of cancer. Long-chain fatty acids are the building blocks of biomembranes, and $\sim 95 \%$ of saturated and monosaturated fatty acids constitute nutrients for cancer cell growth. Thus, fatty acid synthesis plays an important role in carcinogenesis (23). ACCA is a key enzyme in fatty acid synthesis. ACCA RNAi reduces the pool of palmitic acid, and ACCA gene expression is upregulated in many cancer tissues. High ACCA expression has been associated with poor prognoses in patients (13-15). Therefore, fatty acid synthesis may be a potential target for cancer therapy.

TOFA is a specific ACCA inhibitor and it increases fatty acid oxidation and ketogenesis by exerting allosteric inhibition on ACCA $(17,18)$. According to Wang et al $(15)$, TOFA was shown to be cytotoxic to human lung and colon cancer cells via inhibition of the fatty acid synthesis pathway. The present 
A

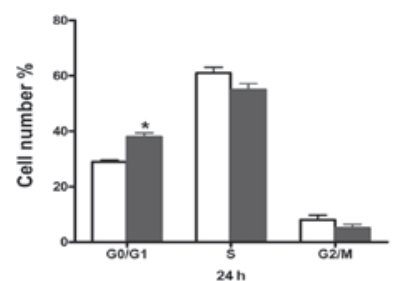

C

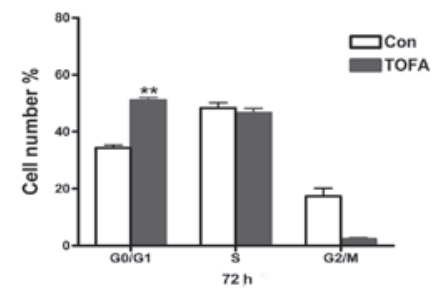

$\mathbf{E}$

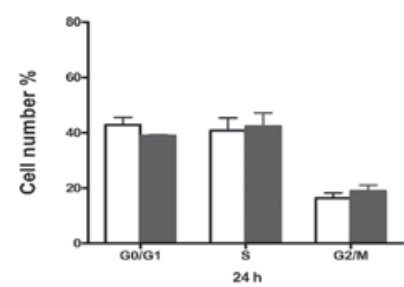

G

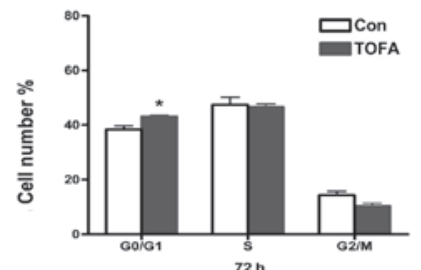

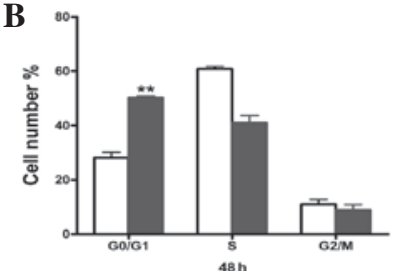

D

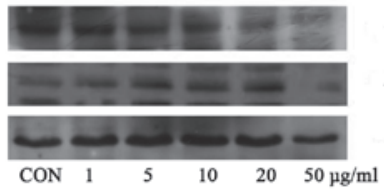

F

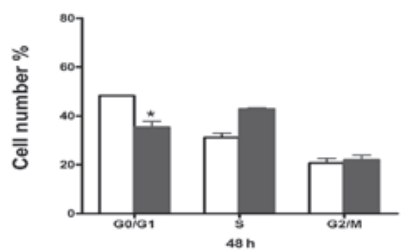

$\mathbf{H}$

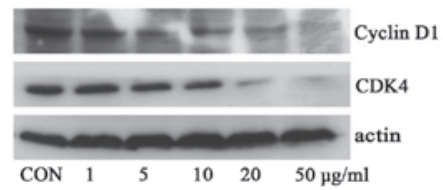

Figure 2. Cells treated with TOFA arrest in the G0/G1 phase. The cells were plated in 6-well plates $\left(2 \times 10^{5} /\right.$ well) with or without TOFA for 24,48 and $72 \mathrm{~h}$. The numbers of cells in the G0/G1, S and G2/M phase were detected by FACScan analysis. The experiments were repeated three times; $\mathrm{P}<0.05$ and ${ }^{* *} \mathrm{P}<0.01$ compared with control cells. (A-C) COC1 cells were arrested in the G0/G1 phase when treated with TOFA ( $5 \mu \mathrm{g} / \mathrm{ml})$ for 24,48 and $72 \mathrm{~h}$. (E-G) COC1/DDP cells were arrested in the G0/G1 phase when treated with TOFA $(10 \mu \mathrm{g} / \mathrm{ml})$ for 24,48 and $72 \mathrm{~h}$. (D and H) Cyclin D1 and CDK4 protein expression was assessed by western blot analysis. COC1 and COC1/DDP cells were treated with various concentrations of TOFA as indicated for $24 \mathrm{~h}$, and cell lysates were harvested for immunoblotting. $\beta$-actin served as a loading control. TOFA, 5-tetradecyloxy-2-furoic acid; CDK4, cyclin-dependent kinase 4.

A

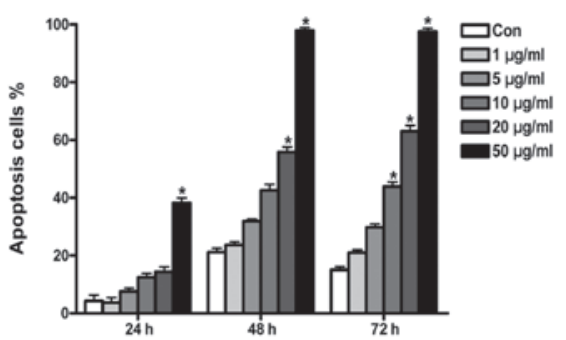

C

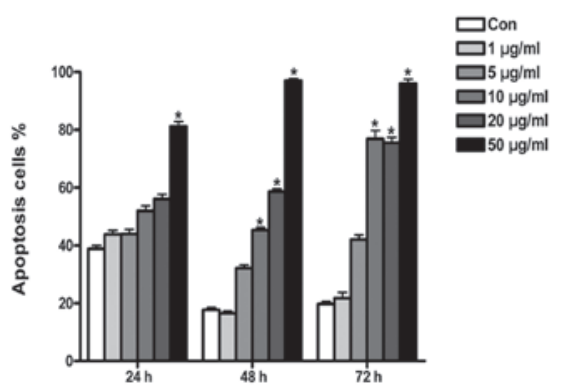

B

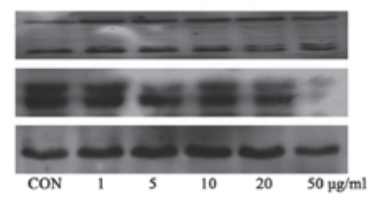

D

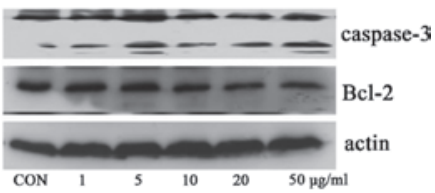

Figure 3. TOFA induces apoptosis in ovarian cancer cells. (A and C) FACScan analysis. COC1 and COC1/DDP cells were treated with TOFA ( $0,1,5,10$, 20 and $50 \mu \mathrm{g} / \mathrm{ml}$ ) for 24, 48 and $72 \mathrm{~h}$. The cells were collected and subjected to FACScan analysis as described in Materials and methods. All data represent mean values and error bars represent the SD of three samples in independent experiments repeated three times; " $\mathrm{P}<0.05$ compared with control groups. (B and D) Caspase-3 and Bcl-2 were detected by western blot analysis. COC1 and COC1/DDP cells were treated with TOFA for $24 \mathrm{~h}$ and cell lysates were harvested for immunoblotting. $\beta$-actin was used as a loading control. TOFA, 5 -tetradecyloxy-2-furoic acid. 
A

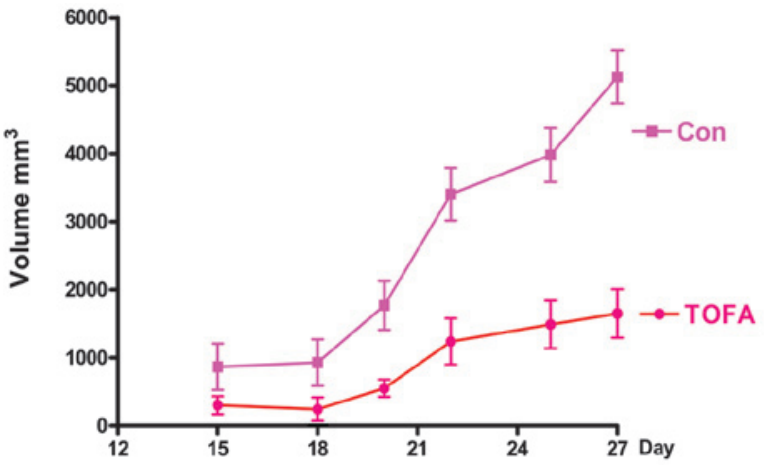

B

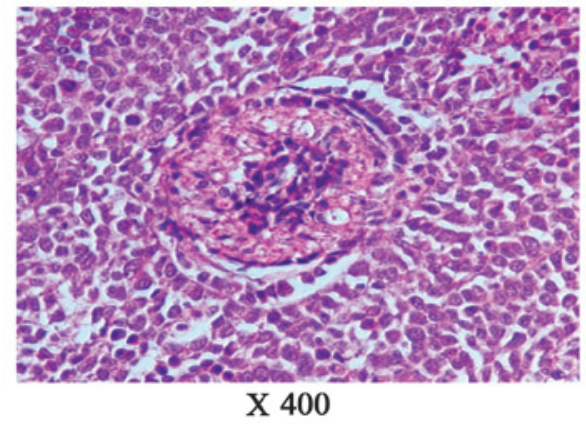

Figure 4. TOFA suppresses human ovarian tumor growth in vivo. (A) Growth curves of COC1/DDP tumors in nude mice treated with dimethylsulfoxide (DMSO; Con) and TOFA. (B) Representative image of H\&E staining of TOFA-treated tissues. Data represent the mean \pm SD (error bars). TOFA, 5-tetradecyloxy-2-furoic acid; H\&E, hematoxylin and eosin.

study showed that TOFA exerts a highly cytotoxic effect on ovarian cancer $\mathrm{COC} 1$ and $\mathrm{COC} 1 / \mathrm{DDP}$ cell proliferation in a dose- and time-dependent manner. TOFA was also shown to arrest cancer cells in the G1 phase as well as to induce apoptosis. These results are in agreement with similar findings in the lung cancer cell line NCI-H460 and the colon cancer cell lines HCT-8 and HCT-15.

To investigate whether TOFA suppresses tumor proliferation in vivo, we examined the effect of TOFA using a human ovarian cancer mouse xenograft model (24). The results showed that the tumor growth rate was significantly inhibited by TOFA when compared with the control mice, and no toxicity was observed in the histological samples of several important organs.

The present study showed that ovarian cancer cell growth was effectively inhibited in vitro when TOFA was used at concentrations of $1-50 \mu \mathrm{g} / \mathrm{ml}$ (Fig. 1). The number of cells in the cell cycle phases was counted using FACScan analysis. When the cells were treated with $10 \mu \mathrm{g} / \mathrm{ml}$ TOFA for $72 \mathrm{~h}$, the percentage of cells arrested in the G0/G1 phase was higher compared with that of the control cells (Fig. 2). Therefore, we hypothesized that TOFA suppresses ovarian cancer cell proliferation by arresting cells in the G0/G1 phase. Cyclin D1 is an integral regulator of the G1 phase and is overexpressed in several types of cancer, such as ovarian, lung and breast cancer (25). Cyclin 1 may be closely associated with invasive ovarian cancer, although no impact on clinical outcomes has been observed. CDK proteins, a family of serine/threonine kinases, tightly regulate the cell cycle at multiple points. Activation of the CDK protein by binding to its cyclin partner controls cell cycle progression. Overexpression of CDK4 is often associated with increased cyclin D1 expression (25). Growth stimulators induce cyclin D1 expression and the formation of a cyclin D1-CDK4 complex, leading to G1 to S phase transition. Cyclin D1/CDK4 complex plays an important role in maintaining normal cell division (26). Ray et al (27) confirmed that the BRCA1/ACC complex regulates the cell cycle by phosphorylating the $\operatorname{Ser}^{1263}$ residue of ACC (27). In the present study, cyclin D1 expression was shown to be decreased by exposure to TOFA and the cells were found to be arrested in the G1 phase. Therefore, the inhibition or regulation of ACCA activity constitutes a potential mechanism that could suppress cancer cell proliferation.
According to a previous study (24), TOFA was shown to have no cytotoxic effect on the ovarian cancer cell line SKOV-3, after a 24-h treatment. Moreover, TOFA treatment did not lead to AMPK phosphorylation (24). However, according to the results of the present study, TOFA induced apoptosis in the ovarian cancer cell lines COC1 and COC1/DDP, as measured by FACScan analysis. The cells were exposed to TOFA $(10 \mu \mathrm{g} / \mathrm{ml})$ for $72 \mathrm{~h}$, and the percentage of apoptotic cells was higher compared with that of the untreated cells. Moreover, we observed that caspase-3 was cleaved and activated, and that $\mathrm{Bcl}-2$ protein levels were slightly decreased after TOFA treatment of both COC1 and COC1/DDP cells. Consequently, the apoptosis pathway is suggested to constitute one of the mechanisms underlying TOFA action in inducing cell death.

To the best of our knowledge, this is the first study indicating that the ACCA inhibitor TOFA is a suppressor of ovarian cancer cell proliferation in vitro and in vivo. TOFA was shown to arrest the cells in the G0/G1 phase as well as to induce apoptosis. Therefore, the inhibition of ACCA activity is suggested to be a potential target of future cancer therapies.

\section{Acknowledgements}

This work was supported by grants from the Shanghai Health Bureau Key Disciplines and Specialties Foundation, Shanghai Education Commission Key Disciplines Foundation, Key Discipline Project of Ren Ji Hospital, Shanghai Jiao Tong University School of Medicine, the National Natural Science Foundation of China (no. 81072137), and the Funding Scheme for Training Young Teachers in Colleges and Universities in Shanghai (no. ZZjdyx12066).

\section{References}

1. Jemal A, Bray F, Center MM, Ferlay J, Ward E and Forman D: Global cancer statistics. CA Cancer J Clin 61: 69-90, 2011.

2. Eltabbakh GH and Awtrey CS: Current treatment for ovarian cancer. Expert Opin Pharmacother 2: 109-124, 2001.

3. Herzog TJ: The current treatment of recurrent ovarian cancer. Curr Oncol Rep 8: 448-454, 2006.

4. Wakil SJ, Stoops JK and Joshi VC: Fatty acid synthesis and its regulation. Annu Rev Biochem 52: 537-579, 1983.

5. Barber MC, Price NT and Travers MT: Structure and regulation of acetyl-CoA carboxylase genes of metazoa. Biochim Biophys Acta 1733: 1-28, 2005. 
6. Griffin MJ and Sul HS: Insulin regulation of fatty acid synthase gene transcription: roles of USF and SREBP-1c. IUBMB Life 56: 595-600, 2004.

7. Hardie DG and Pan DA: Regulation of fatty acid synthesis and oxidation by the AMP-activated protein kinase. Biochem Soc Trans 30 (Pt 6): 1064-1070, 2002.

8. Abu-Elheiga L, Brinkley WR, Zhong L, Chirala SS Woldegiorgis G and Wakil SJ: The subcellular localization of acetyl-CoA carboxylase. Proc Natl Acad Sci USA 97: 1444-1449, 2000.

9. Chen ZP, McConell GK, Michell BJ, Snow RJ, Canny BJ and Kemp BE: AMPK signaling in contracting human skeletal muscle: acetyl-CoA carboxylase and NO synthase phosphorylation. Am J Physiol Endocrinol Metab 279: E1202-E1206, 2000.

10. Milgraum LZ, Witters LA, Pasternack GR and Kuhajda FP: Enzymes of the fatty acid synthesis pathway are highly expressed in in situ breast carcinoma. Clin Cancer Res 3: 2115-2120, 1997.

11. Witters LA, Widmer J, King AN, Fassihi K and Kuhajda F: Identification of human acetyl-CoA carboxylase isozymes in tissue and in breast cancer cells. Int J Biochem 26: 589-594, 1994

12. Yahagi N, Shimano H, Hasegawa K, Ohashi K, Matsuzaka T, Najima Y, Sekiya M, Tomita S, Okazaki H, Tamura Y, Iizuka Y, Ohashi K, Nagai R, Ishibashi S, Kadowaki T, Makuuchi M, Ohnishi S, Osuga J and Yamada N: Co-ordinate activation of lipogenic enzymes in hepatocellular carcinoma. Eur J Cancer 41: 1316-1322, 2005.

13. Chajès V, Cambot $\mathrm{M}$, Moreau $\mathrm{K}$, Lenoir GM and Joulin V: Acetyl-CoA carboxylase alpha is essential to breast cancer cell survival. Cancer Res 66: 5287-5294, 2006.

14. Brusselmans K, De Schrijver E, Verhoeven G and Swinnen JV: RNA interference-mediated silencing of the acetyl-CoAcarboxylase-alpha gene induces growth inhibition and apoptosis of prostate cancer cells. Cancer Res 65: 6719-6725, 2005.

15. Wang C, Xu C, Sun M, Luo D, Liao DF and Cao D: Acetyl-CoA carboxylase-alpha inhibitor TOFA induces human cancer cell apoptosis. Biochem Biophys Res Commun 385: 302-306, 2009.

16. McCune SA and Harris RA: Mechanism responsible for 5-(tetradecyloxy)-2-furoic acid inhibition of hepatic lipogenesis. J Biol Chem 254: 10095-10101, 1979.

17. Tong L and Harwood HJ Jr: Acetyl-coenzyme A carboxylases: versatile targets for drug discovery. J Cell Biochem 99 1476-1488, 2006.
18. Harwood HJ Jr: Treating the metabolic syndrome: acetyl-CoA carboxylase inhibition. Expert Opin Ther Targets 9: 267-281, 2005.

19. Halvorson DL and McCune SA: Inhibition of fatty acid synthesis in isolated adipocytes by 5 -(tetradecyloxy)-2-furoic acid. Lipids 19: 851-856, 1984.

20. Guseva NV, Rokhlin OW, Glover RA and Cohen MB: TOFA (5-tetradecyl-oxy-2-furoic acid) reduces fatty acid synthesis, inhibits expression of AR, neuropilin-1 and Mcl-1 and kills prostate cancer cells independent of p53 status. Cancer Biol Ther 12: 80-85, 2011.

21. Oda T, Hayano T, Miyaso H, Takahashi $\mathrm{N}$ and Yamashita $\mathrm{T}$ : Hsp90 regulates the Fanconi anemia DNA damage response pathway. Blood 109: 5016-5026, 2007.

22. Zhong Q, Wen YJ, Yang HS, Luo H, Fu AF, Yang F, Chen LJ, Chen X, Qi XR, Lin HG, Wan Y, Chen XC, Wei YQ and Zhao X: Efficient inhibition of cisplatin-resistant human ovarian cancer growth and prolonged survival by gene transferred vesicular stomatitis virus matrix protein in nude mice. Ann Oncol 19: 1584-1591, 2008.

23. Kuhajda FP: Fatty-acid synthase and human cancer: new perspectives on its role in tumor biology. Nutrition 16: 202-208, 2000.

24. Zhou W, Han WF, Landree LE, Thupari JN, Pinn ML, Bililign T, Kim EK, Vadlamudi A, Medghalchi SM, El Meskini R, Ronnett GV, Townsend CA and Kuhajda FP: Fatty acid synthase inhibition activates AMP-activated protein kinase in SKOV3 human ovarian cancer cells. Cancer Res 67: 2964-2971, 2007.

25. D'Andrilli G, Kumar C, Scambia G and Giordano A: Cell cycle genes in ovarian cancer: steps toward earlier diagnosis and novel therapies. Clin Cancer Res 10: 8132-8141, 2004.

26. Aggarwal P, Vaites LP, Kim JK, Mellert H, Gurung B, Nakagawa H, Herlyn M, Hua X, Rustgi AK, McMahon SB and Diehl JA: Nuclear cyclin D1/CDK4 kinase regulates CUL4 expression and triggers neoplastic growth via activation of the PRMT5 methyltransferase. Cancer Cell 18: 329-340, 2010.

27. Ray H, Suau F, Vincent A and Dalla Venezia N: Cell cycle regulation of the BRCA1/acetyl-CoA-carboxylase complex. Biochem Biophys Res Commun 378: 615-619, 2009. 